\title{
The added value of rating pictograms for sustainable hotels in classified ads
}

\author{
Vinzenz, Friederike
}

\begin{abstract}
In making online hotel booking decisions, people use consumer ratings as a cue to evaluate previous customers' experiences with the promoted hotel. Currently, hotels' sustainability efforts are an important additional criterion that factors into customers' booking behavior. However, the effectiveness of certifying such efforts with sustainability labels is questionable. An experiment was conducted with 684 participants to examine the effectiveness of two different certification systems beyond the persuasive power of customer ratings. To analyze these effects, a 3 (customer rating: poor vs. mediocre vs. good) $\times 3$ (sustainability level: one vs. two vs. three) $\times 2$ (certification system: label vs. rating pictogram) mixed design was used. The results showed that consumers must be able to understand the informational cues that indicate the level of sustainability if they are to use this information in addition to the valence of the overall customer rating as a decision-making criterion.
\end{abstract}

DOI: https://doi.org/10.1016/j.tmp.2018.10.006

Posted at the Zurich Open Repository and Archive, University of Zurich ZORA URL: https://doi.org/10.5167/uzh-161676

Journal Article

Accepted Version

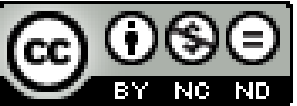

The following work is licensed under a Creative Commons: Attribution-NonCommercial-NoDerivatives 4.0 International (CC BY-NC-ND 4.0) License.

Originally published at:

Vinzenz, Friederike (2019). The added value of rating pictograms for sustainable hotels in classified ads. Tourism Management, 29:56-65.

DOI: https://doi.org/10.1016/j.tmp.2018.10.006 


\title{
The added value of rating pictograms for sustainable hotels in classified ads
}

\author{
Friederike Vinzenz
}

Department of Mass Communication and Media Research, University of Zurich, Zurich, Switzerland

\section{Corresponding author:}

Friederike Vinzenz (f.vinzenz@ikmz.uzh.ch) is a doctoral candidate at the Division of Media Psychology and Effects at the University of Zurich, +49 (0)44 63520 74, Andreasstrasse 15, 8050 Zurich, Switzerland.

\section{Acknowledgements:}

This research has not been funded by any organization. The experiment was part of the doctoral thesis of Friederike Vinzenz, under supervision of Prof. Dr. Werner Wirth from the University of Zurich. Prof. Dr. Juliana Priskin from the Lucerne University of Applied Sciences and Arts was consulted for proof reading.

Declarations of interest: none

This research did not received any specific grant from funding agencies in the public, commercial, or non-for-profit sector. 


\section{Abstract}

2 In making online hotel booking decisions, people use consumer ratings as a cue to

3 evaluate previous customers' experiences with the promoted hotel. Currently, hotels'

4 sustainability efforts are an important additional criterion that factors into customers' booking

5 behavior. However, the effectiveness of certifying such efforts with sustainability labels is

6 questionable. An experiment was conducted with 684 participants to examine the effectiveness of

7 two different certification systems beyond the persuasive power of customer ratings. To analyze

8 these effects, a 3 (customer rating: poor vs. mediocre vs. good) x 3 (sustainability level: one vs.

9 two vs. three) x 2 (certification system: label vs. rating pictogram) mixed design was used. The

10 results showed that consumers must be able to understand the informational cues that indicate the

11 level of sustainability if they are to use this information in addition to the valence of the overall

12 customer rating as a decision-making criterion.

13 Keywords: online reviews; customer rating; sustainability certification; sustainability

14 level; decision-making; information seeking; trustworthiness 


\section{Introduction}

Due to increased hotel bookings through online platforms (Buhalis \& Law, 2008), the

17 effectiveness of short and easily interpreted information has become increasingly important.

18 Many factors, such as location, hotel size, room quality, price, and cleanliness, influence

19 consumers' booking decisions (Radojevic, Stanisic, \& Stanic, 2015; Ramanathan \& Ramanathan,

20 2011). Therefore, consumers are constantly confronted with various types of product and service

21 information on different webpages. To reduce the amount of information, customers usually use

22 search engines or online travel agencies to receive a preselection of hotel offers (Murphy, Chen

$23 \&$ Cossutta, 2016). When booking a hotel online, customers select key attributes first and then,

24 on the basis of classified ads, select an offer that might be of interest for further consideration

25 (Booking.com; TripAdvisor.com). The proposed hotel selection meets the determined criteria but

26 remains extensive, whereby classified ads include only a few informational cues that set the basis

27 for the consideration choice. Hence, during this selection phase, quality signals such as brands,

28 labels, hotel classifications, and customer ratings are an important persuasive tool that helps

29 consumers to select (Decrop \& Boembeke, 2017; Hu, Chen, \& Chou, 2017; Lien, Wen, Huang,

30 \& Wu, 2015; Sparks, Perkins, \& Buckley, 2013).

Consumer-generated reviews and the recommendations of friends are found to be the

32 most important factors that influence hotel bookings (Dickinger \& Mazanec, 2008; Ye, Law, Gu,

$33 \&$ Chen, 2011). These information sources provide cues about whether previous customers had

34 positive or negative experiences with a hotel (Filieri \& McLeay, 2014). Therefore, such sources

35 represent an evaluation of all tangible and intangible aspects of the hotel. Due to the persuasive

36 power of such recommendations, an increasing number of online sellers include consumer

37 reviews and ratings on their websites (Chen \& Xie, 2008). Beyond written online reviews, 
suppliers such as Tripadvisor.com provide classified ads, which include numerical customer ratings that summarize all consumer evaluations of the promoted hotel. Thus, the customer rating represents the evaluation of various hotel attributes, made by several previous consumers, and serve as quality signals during the early stage of the decision-making process.

In addition to customer ratings, which are a well-established persuasive tool, selected

43 quality attributes can be certified and highlighted in an advertisement. Because sustainability is

44 an important attribute for the tourism and hospitality sector, advertisements increasingly use

45 labels to certify the social, environmental and ecological responsibility of a hotel (Bickart \&

46 Ruth, 2012). Following the United Nations Brudtland Report in 1987, numerous guidelines,

47 agreements, and alliances were established to implement sustainability. Several public, private

48 and nonprofit players developed a large number of certification programs with different criteria,

49 content, implementation regulations, and scopes (Buckley, 2002; Font, 2002). Some certify only

50 environmental sustainability, while others certify all three dimensions of sustainability

51 (environmental, social, and economic) (Tepelus \& Córdoba, 2005). The variety of certification

52 programs and associated sustainability labels together with the nontransparent diversity of the

53 criteria cause customer confusion (Font, 2002; Lübbert, 2001). To obtain details about the scope

54 of the certification program and to learn about the criteria, customers must search for further

55 information. The label symbol itself does not provide information on the certification criteria.

56 Hence, customers cannot identify the different scopes of several labels. Moreover, the label does

57 not visualize the compliance rate. The label is a sign for a whole certification program, including

58 various criteria for which the hotel must fulfill a certain amount to be certified. Thus, labels have

59 no gradation displayed, and the only reference point is 'no label'. In contrast, rating scales

60 provide a point of reference, which allows differentiation and quality rankings. Rating scales are 
61 a well-established tool in the consumer product industry to show qualitative differences (Chen \&

62 Xie, 2008; Clemons, Gao, \& Hitt, 2006; Sparks \& Browning, 2011; Willemsen, Neijens,

63 Bronner, \& de Ridder, 2011). Such rating scales might be a good alternative to labels to identify

64 the sustainability of a hotel in a way that is quick and easy to interpret. A symbol in the form of

65 sustainability rating pictogram could be included in classified ads together with an overall

66 quality cue, such as a customer rating, to influence consumers' interest in obtaining further hotel

67 information.

As online viewers usually have only limited capacity and time to handle a large amount

69 of information (Hu, Chen, \& Chou, 2017), product and service qualities as well as other hotel

70 attributes should be, in the early stage of an online booking decision, communicated by short and

71 easy-to-interpret informational cues to attract consumers' attention and to be persuasive. The

72 current paper focuses on the effect of such short informational cues and investigates how

73 informational cues that are included in classified ads influence consumers' interest in obtaining

74 further hotel information. Do people prefer hotels with a positive consumer rating? How useful

75 to the decision process are certifications for sustainability? An experimental study on the impact

76 of customer ratings and different sustainability certifications on consumers' interest in obtaining

77 further information was conducted to explore these questions. The persuasiveness of consumer

78 reviews is well documented in the previous research (Dickinger \& Mazanec, 2008; Filieri \&

79 McLeay, 2014; Sparks \& Browning, 2011; Vermeulen \& Seegers, 2009; Zhao, Wang, Guo, \&

80 Law, 2015); however, to date only a small number of researchers have empirically analyzed the

81 impact of the overall numerical customer rating summarizing all online reviews on consumer

82 interest (Gavilan, Avello, \& Martinez-Navarro, 2018). Therefore, the study examines how

83 customer ratings influence interest in obtaining detailed information on the promoted hotel 
84 during an early stage of the decision-making process. In addition to consumer reviews that

85 influence decision-making, sustainability is an important quality attribute (Bickart \& Ruth, 2012;

86 Chen, 2015; Fairweather, Maslin, \& Simmons, 2005; Sparks \& Browning, 2011). The

87 sustainability aspects of a hotel might influence consumers' decisions in addition to the customer

88 rating if the certification of these aspects is included in the classified ads and designed in a

89 comprehensible manner. Therefore, the current study compares the effectiveness and

90 trustworthiness of two different sustainability certification systems. The benefits of a

91 sustainability certification that displays different levels of sustainability are presented as well as

92 the interaction between customer rating pictograms and sustainability rating pictograms will be 93 explored.

2 Theoretical background

\section{$95 \quad 2.1$ Online booking}

For decades, the hotel and hospitality research has investigated the question of the factors that influence the decision to book an accommodation (Dickinger \& Mazanec, 2008; Öğüt \&

98 Onur Taş, 2012; Radojevic, Stanisic, \& Stanic, 2015; Ramanathan \& Ramanathan, 2011; Rhee \& 99 Yang, 2015; Yang, Mueller, \& Croes, 2016). It was found that the intangible service elements and 100 tangible physical features of a hotel are evaluated and judged by the customer to estimate the

101 hotel quality. Thus, the customer needs information about the hotel's attributes and descriptions

102 of the consumer experience of the hotel. If customers lack first-hand experience, they use online

103 travel agencies (e.g., Booking.com), online travel communities (e.g., TripAdvisor.com) and

104 various forms of consumer-generated content (e.g., travel blogs) as a primary means of

105 determining the quality attributes of a hotel (Guillet \& Law, 2010; Sun, Law, Luk, \& Fong,

106 2017). Such booking webpages usually provide a choice of hotels presented by classified ads, 
107 after the customer selects key attributes based on personal preferences. Because online viewers

108 usually have limited capacity to handle a large amount of information $(\mathrm{Hu}, \mathrm{Chen}, \& \mathrm{Chou}$,

109 2017), these classified ads provide only a limited amount of information about the hotel's

110 attributes, and quality signals are significant influencing informational cues during the early

111 decision stage (Decrop \& Boembeke, 2017).

\section{$112 \quad 2.2$ Customer ratings}

113 Electronic word-of-mouth, such as online reviews and online recommendations, are an important

114 tool for increasing the demand of a hotel (Dickinger \& Mazanec, 2008; Filieri \& McLeay, 2014;

115 Litvin, Goldsmith, \& Pan, 2008; Ye, Law, \& Gu, 2009). Customers base their decisions to book

116 an accommodation on the valence and number of online reviews (Gavilan et al., 2018). Positive

117 or negative word-of-mouth can play a decisive role in convincing a potential customer to either

118 book or not book a promoted hotel. For example, Dickinger and Mazanec (2008) showed that the

119 experiences of previous customers expressed through online reviews are the most important

120 factor for online booking decisions. Sparks and Browning (2011) investigated how different

121 aspects of online reviews influence the effect of such reviews. They found that positive online

122 reviews lead to a higher booking intention than negative reviews. This relationship was also

123 shown in several other studies (Lee, Park, \& Han, 2008; Mauri \& Minazzi, 2013; Tan, Lv, Liu,

124 \& Gursoy, 2018; Vermeulen \& Seegers, 2009; Zhao et al., 2015). Vermeulen and Seegers (2009)

125 argue that both positive and negative reviews increase consumers' awareness of a hotel;

126 however, positive reviews positively influence the consideration of an offer. Thus, if a consumer

127 is looking for supporting information to form a booking intention, he or she would rather choose

128 hotels with highly positive reviews, whereas negative reviews strengthen the intention not to

129 book the hotel (Ladhari \& Michaud, 2015; Serra Cantallops \& Salvi, 2014). 
In the early stage of the decision-making process, consumers must choose which offer

131 they will consider to receive additional information: Which offer or hotel is interesting enough to

132 warrant a closer evaluation that involves reading the reviews? On platforms such as TripAdvisor,

133 a summary of all hotel guests' online reviews is shown as a single overall rating on the first page.

134 This numerical rating represents an aggregation of all online reviews (Sparks, Kam Fung So, \&

135 Bradley, 2016; Willemsen et al., 2011). More precisely, it is the average of all numerical

136 consumer evaluations, not including the written responses. Because classified ads usually include

137 only a few informational cues, such as a picture of the hotel or a hotel room, the price and name

138 of the hotel, occasionally hotel highlights, the distance to the city center, and a customer rating.

139 The customer rating as a global quality signal is an important persuasive tool. It is one of the first

140 units of information that help consumers decide which hotel might be interesting to book. As

141 Gavilan, Avello and Martinez-Navarro (2018) showed, a good rating encourages tourists to

142 include a hotel in their consideration set. Hence, a summarized numerical representation of

143 consumer reviews, such as a customer rating, presumably has an effect on consumers' interest in

144 receiving further information.

$145 \mathrm{H} 1$. The higher the hotel is rated by the customer rating, the stronger the potential the 146 guest's interest will be to obtain further information on the associated hotel offer.

\section{$147 \quad 2.3$ Sustainability certifications}

148 Because concerns about sustainability have become more relevant, cues that provide information

149 on the environmental and social impacts of products have been increasingly integrated into

150 advertisements (Bickart \& Ruth, 2012). In addition to advertising statements about sustainability,

151 the tourist and hospitality sector uses labels to certify sustainable tourism. Compared to the

152 absence of a certification, a label helps guests verify advertising messages and improves their 
153 attitudes regarding a hotel (Casaló, Flavián, Guinalíu, \& Ekinci, 2015; Sparks et al., 2013).

154 Because of the demand for sustainability and on the basis of several politically and private155 economic guidelines, several certification programs have been founded. The number of such

156 programs has increased over the past decade, and currently there are many different types of 157 labels that certify the sustainability of hotels (Frydendal, Hansen, \& Bonou, 2018; Kozak \& 158 Nield, 2004; Park \& Millar, 2016; Pröbstl \& Müller, 2012). Each year, new labels are created, 159 and other labels disappear. Some certification programs are international, and others are national

160 or regional. These programs have been developed by nonprofit groups, consumer advocacy

161 groups, government agencies and for-profit groups. Due to the absence of effective legal or

162 political rules, these actors determine their own policies. As a result, the voluntary codes, awards,

163 and accreditation and certification schemes of the labels vary considerably (Buckley, 2002).

164 This multitude of labeling systems adds to customer confusion (Lübbert, 2001) regarding,

165 on the one hand, the scope of a particular program and, on the other hand, the practical

166 implementation of the hotel. First, although the definition of sustainable tourism implies that

167 ecological, social and economic goals are pursued simultaneously and equally (UNEP \&

168 UNWTO, 2005), some certification programs verify only the environmental aspects of hotels,

169 while other programs certify the environmental, social and economic aspects. Programs that

170 certify only the environmental dimension are not necessarily based on fewer criteria than the

171 other programs, but they monitor and certify just one dimension out of three possible

172 sustainability dimensions. However, because certification programs are neither coordinated nor

173 standardized, and they have no uniform labeling rules, it is impossible for customers to

174 determine the scope of a program by just seeing the label symbol in the advertising. Costumers

175 need more information about a certification program to understand what the label stands for. For 
176 example, the well-known certification program Green Globe assigns one symbol to certify

177 sustainable hotels, but the label does not include information about the scope of the program. If a

178 customer wishes to learn more about a label's criteria, they must visit the website of the

179 certification program. Second, certification guidelines are not always entirely published, and the

180 degree of compliance cannot be reviewed (Graci \& Dodds, 2015). Hotels might fulfill 70\% or

$18190 \%$ of the criteria. Generally, an advertisement will include a particular label without informing

182 the consumer about the compliance rate. Although there are a few certification programs, such as

183 the ibex fairstay, that award hotels with different types of labels depending on the achieved

184 performance (e.g., ibex bronze, ibex silver, ibex gold, ibex platinum), the individual symbol

185 itself does not provide a gradation. If consumers see the label, they do not know if, for example,

186 silver is the second or third highest award. They must search for information to obtain further

187 details; however, the label does not show how many of the potential criteria are met by a hotel.

188 In sum, although labels are commonplace and are used to persuade consumers, the actual

189 effectiveness and efficiency of their impact has been questioned (Dendler, 2014; Fairweather et

190 al., 2005; Font, 2002; Horne, 2009; Rex \& Baumann, 2007). There are numerous certification

191 programs with different scopes and various criteria (Buckley, 2002; Font, 2002); however, the

192 symbols that are used by these programs to certify hotels do not include any information about

193 those scopes or criteria. Hence, differences among certification programs are often difficult to

194 determine. Consumers cannot distinguish the different information that is represented by the

195 different labels. For example, Grössling and Buckley (2016) found that labels suffer from a lack

196 of persuasive communication. They showed that tourists largely ignored carbon labels in tourism

197 because they did not understand the information provided by the label. Consumers found the

198 label to be of no importance, too abstract, or lacking an opportunity for comparison. Comparably, 
199 Grunert, Hieke and Wills (2014) analyzed the relationships among consumers' motivations and

200 their understanding of and reliance on sustainability labels on food products. Their results

201 showed that consumers have a low understanding of certifications and consider them to have

202 little utility. As a consequence of the understanding and differentiation problem, labels suffer

203 from a lack of persuasive power, and customers do not consider the different labels in their

204 consideration set.

205 H2. Labels that represent different sustainability scopes do not influence guests' interest

206 in obtaining further information about the associated hotel offer.

207 However, visual elements and additional information partly improve the ability of

208 consumers to understand and process sustainability claims. For example, traffic light color

209 systems and further information about a label increases consumers' understanding and

210 orientation (Emberger-Klein \& Menrad, 2018). One advantage of a traffic light color system is

211 that consumers are familiar with this schema. Therefore, they can easily apply it. Customer rating

212 is another scale that is familiar to consumers. In contrast to the traffic light system, customer

213 ratings provide more gradations, and a product evaluation encompasses a positive range. The

214 traffic light system has three gradations: red, yellow, and green. By contrast, customer ratings

215 usually have five to ten gradations, from 'low' or 'poor quality' to 'excellent quality'. Hence,

216 rating pictograms can represent the level of sustainability in a more differentiated way that is not

217 limited to displaying whether a hotel is 'not meeting sustainability standards' (red), 'meeting

218 standards' (yellow) or 'performing well on sustainability' (green).

219 On popular online shopping websites, Amazon.com in particular, customer ratings have

220 been used as quality signals for decades (Chen \& Xie, 2008; Willemsen et al., 2011). As such

221 rating scales provide a reference point, potential consumers can identify the evaluations of other 
222 consumers. They can estimate the relative satisfaction of people with a product simply by

223 viewing the rating pictogram without even reading all the corresponding customer

224 recommendations that contribute to the overall rating. Although it is not common that

225 sustainability certifications are included in classified ads, to include such a rating pictogram to

226 represent the level of sustainability performance could be very useful. As such a symbol shows in

227 an easy-to-interpret way how sustainable a hotel is, this rating pictogram might have an effect on

228 the booking behavior. In other words, a sustainability rating pictogram provides a reference point

229 and therefore shows the compliance rate of a hotel's sustainability performance and could be

230 useful during the early stage of the decision-making process in determining which hotel might be

231 of interest for further consideration.

232 H3. If the level of sustainability is represented by a rating pictogram, a higher

233 sustainability performance increases guests' interest.

234 For two reasons, this study proposes that customers also trust sustainability ratings more

235 than sustainability labels: Consumers' familiarity and experience with ratings (Gefen, 2000)

236 together with the perception that the rating is provided by a noncommercial source (Ha, 2002)

237 lead to high perceived credibility. First, the increase in information available on products through

238 several distribution channels has also increased the utility of informational shortcuts for

239 reference purposes. Websites have integrated rating systems that display reviewers' assessments

240 of products and services. Therefore, consumers are familiar with rating scales, which are often

241 shown in the form of five-point star recommendations. The more familiar a person is with a

242 certain type of information, the more he or she trusts the information received. The tendency to

243 trust in messages based solely on repeated exposure is widely supported by research on the 'truth

244 effect' (Hasher, Goldstein, \& Toppino, 1977; Unkelbach, 2007). Second, the increase in the 
245 number of sustainability labels has also increased the concern of greenwashing. Based on the

246 growing importance of sustainability and the ability to use this aspect to increase company value,

247 companies occasionally use green advertising as a tool to overstate their ecological engagement

248 (Naderer, Schmuck, \& Matthes, 2017). As consequence, consumers might assume commercial

249 interest and mistrust advertised sustainability claims. As information about certification

250 programs is not readily available, the consumer does not know who might have a financial

251 interest in the certification and who stands behind the label. In contrast, it is generally expected

252 that a noncommercial community (e.g., customers) generates the ratings. The tendency to place

253 more trust in a third-party certification is widely supported (Jiang, Jones, \& Javie, 2008; M. K.

254 O. Lee \& Turban, 2001). To summarize, consumers might place more trust in sustainability

255 rating pictograms because of their familiarity with them (truth effect) and because they perceive

256 that a noncommercial community produces the ratings (third-party effect).

257 H4. Consumers will place more trust in sustainability rating pictograms than in

258 sustainability labels.

\subsection{Additional information}

260 Today, numerous informational cues such as ratings and labels have become established in the

261 tourism industry. During the early stage of the online decision-making process, potential guests

262 must decide on the basis of classified ads which offer might be worth considering further. As

263 consumer reviews are the most important predictor of online booking decisions (Dickinger \&

264 Mazanec, 2008), the summarized version of customer ratings may be very influential in this early

265 phase of the selection process. Generally, customer ratings provide information on various

266 aspects of an offer. Hotel guests evaluate intangible service elements and tangible, physical

267 features. Therefore, ratings are considered to be an overall evaluation of all the quality attributes 
268 of a hotel, whereas if a particular quality attribute is certified, only one of many aspects is

269 considered. Sustainability certifications specifically consider the environmental, social and

270 economic attributes of a hotel. Sustainability as an additional quality attribute might also

271 influence the decision-making process (Millar \& Baloglu, 2011), if an easy-to-interpret symbol is

272 integrated into classified ads. Therefore, the study proposes that consumers' interest in additional

273 information is mainly affected by the overall evaluation of an offer (customer rating); however, a

274 certification of particular quality attributes, such as the sustainability of the hotel, can

275 additionally increase interest in obtaining further information if the tourist finds the certification

276 understandable (rating pictogram).

277 H5. Consumers' interest in obtaining more information is mainly influenced by the

278 customer rating, and, in addition, this interest depends on the level of sustainability if the

279 sustainability performance is certified by a rating pictogram.

\section{Method}

\section{$281 \quad 3.1$ Overview}

282 To investigate the proposed hypotheses, a 3 × 3 × 2 experimental design, with two within factors

283 and one between factor, was conducted. Based on actual advertisements, hotel classified ads

284 were created that included, among other things, a customer rating (rated: poor vs. mediocre vs.

285 good) and a sustainability certification (level: one vs. two vs. three). One experimental group

286 viewed ads with the sustainability certification shown as a label. The other experimental group

287 viewed the advertisements with the sustainability certification shown as a rating pictogram.

288 Other elements of the ads were held constant between the within conditions and between the

289 experimental groups. To summarize, the experiment was a 3 (customer rating: poor vs. mediocre

290 vs. good) x 3 (sustainability level: one vs. two vs. three) x 2 (certification system: label vs. rating 
291 pictogram) mixed design; the first two factors were within factors, and the last was a between

292 factor.

\section{$293 \quad 3.2$ Stimuli}

294 Based on actual classified ads, hotel ads were created for this experiment that included a picture, 295 a hotel name, the location of the hotel, information and map pictograms, a manipulated customer 296 rating and a sustainability certification (see appendix A). The consumer rating varied depending 297 on three conditions. In the first condition, where the hotel was rated low, one out of five circles 298 was highlighted yellow (similar to TripAdvisor.com). Three circles were highlighted in yellow in 299 the middle condition, and four and a half circles were highlighted in the high condition. This 300 gradation created variation within the different customer ratings, without generating 301 unrealistically high customer ratings. The sustainability certification was indicated by either a 302 label or by a fictional sustainability rating. First, commercial studies and studies from several 303 organizations investigating different sustainability labels used in the tourism sector (Barth, 304 Weber, \& Güntensperger, 2011; Labelinfo.ch, 2018; Niederberger, 2017; Plüss, Zotz,

305 Monshausen, \& Kühhas, 2016) set the basis for categorizing the labels used in the stimulus. For 306 instance, if a label certifies only the environmental aspects of a hotel's sustainability, that label 307 represents the sustainability level one. In contrast, if a label certifies all three dimensions of 308 sustainability (ecological, social and economic), the level of sustainability is three. Thus, the 309 sustainability level indicates whether all three dimensions of sustainability were taken under 310 consideration or if the label certifies the hotel effort of just one or two dimensions of

311 sustainability. The scope of the certification program should not been seen as equal to the

312 amount of criteria represented by the label. However, all labels used in this study were

313 internationally recognized certification programs that certify either one, two or three dimensions 
314 of sustainability. To ensure that the consumers' awareness of and familiarity with the labels did

315 not differ, twenty different labels were pretested. In addition, the pretest ensured that consumer

316 trust did not differ among the labels. Based on the results of this pretest, three labels were chosen

317 that did not differ with regard to awareness, familiarity, and trust; however, these labels varied in

318 their sustainability scope: Green Key (environmental), Viabono (environmental and economic)

319 and Travelife (environmental, social and economic). All three labels included an on-site third-

320 party evaluation and published their criteria (Plüss et al., 2016). Second, a sustainability rating

321 similar to other rating pictograms was created, showing different levels of sustainability using

322 green lotus flowers. This symbol was used because sustainability is commonly symbolized using

323 leaf- and flower-shaped icons and the color green is widely used in the industrial sector to

324 indicate sustainability actions. Thus, one and a half out of five lotus flowers highlighted green

325 symbolized the sustainability level one. Three highlighted flowers symbolized the second level

326 of sustainability, and five highlighted flowers indicated sustainability level three.

327 To prevent other factors from interfering with the manipulation, this study controlled for

328 informational cues that refer to personal preferences. Before the participants received the

329 advertisements, they were presented with a booking screen (comparable to booking webpages

330 such as Booking.com) with the task of choosing a city or area in Europe they wished to visit, a

331 preferred date of travel and the price they were willing to pay. Hotel price is an influential factor

332 affecting booking intention (Chiang \& Jang, 2007). Therefore, no price cue was included in the

$333 \mathrm{ad}$; however, during the task, the participants could select a price range representing what they

334 were willing to spend per night and per person for the hotel. The selected price range reappeared

335 in the stimuli's introductory text but not in the advertisements themselves. The dates that the

336 participants selected for their vacation were not explicitly mentioned in the introductory text. 
337 However, the introductory text mentioned that the following hotels would be available during the

338 selected time. The destination is another significant predictor in regard to booking decisions

339 (Kozak \& Rimmington, 1999). The city or area chosen by the participants during the selection

340 task appeared under the hotel name and was identical for all nine hotels. Hence, all

341 advertisements contained the same area name. Consequently, regardless of the location, price or

342 dates selected, the participants received hotel ads with nine room pictures and nine hotel names.

343 For each city, 162 hotel ads were created. Thus, each picture and hotel was randomly assigned to

344 the given manipulated conditions. To ensure that the included pictures and names did not differ

345 in terms of attractiveness, familiarity or associations, twenty pictures and twenty names were

346 pretested. The pictures of the hotel rooms were very similar to one another and did not include

347 any location cues. All names were fictitious and not associated with any specific brand. For the

348 experiment, the pictures and names with the best results were used. In addition to the customer

349 rating, the sustainability certification, the picture of the room, the hotel name and its location,

350 each advertisement showed information and map pictograms. The information and map

351 pictograms were identical for all hotels. All ads included a pictogram in the right-hand corner

352 that represented the possibility of obtaining further information on the exact location of the hotel.

353 Similarly, all nine hotels included a pictogram that represented the possibility of obtaining more

354 information about the hotel offer.

$355 \quad 3.3$ Procedure

356 The guidelines of the university ethics committee were followed, and all participants were

357 provided information regarding the experiment and consented to participation. As a cover story,

358 all participants were informed that the purpose of the study was to develop and improve an

359 algorithm for an online hotel search engine. The participants were asked to imagine a scenario in 
360 which they were looking for an accommodation. Therefore, the participants selected a city or

361 area in Europe, a date for traveling and the price they were willing to pay per night and per

362 person for the hotel. After they made their choices, the participants were randomly assigned to an

363 experimental group with either a label certification or a rating pictogram certification. Before the

364 stimuli, the participants were provided introductory text that included the price range the

365 participant had selected. Next, the participants viewed nine hotel advertisements, with variations

366 in the customer rating (rated: poor vs. mediocre vs. good) and the sustainability certification

367 (level: one vs. two vs. three). The hotel classified ads appeared in random order. The participants

368 were first asked to rank the hotel offers and then to rate their interest in obtaining more

369 information about each hotel offer based on the perceived attractiveness of the offer. Afterwards,

370 they completed a questionnaire that included a manipulation check and questions regarding trust,

371 sustainable behavior and a few other control items. At the end of the experiment, the participants

372 were debriefed and dismissed.

$373 \quad 3.4$ Participants

374 A professional company that provides online access panels was hired to recruit a representative

375 Swiss sample for this investigation. Switzerland is considered to be a very sustainable destination

376 (Robecosam, 2018; WEF, 2017), and the Swiss people are a high-potential target group (BFS,

377 2018; STV FST, 2017). For the final sample, 13\% of the participants had to be excluded from the

378 panel because they did not seriously participate in the study: People were excluded if they stated

379 that they did not intend to participate seriously, if they did not finish the questionnaire, if their

380 answers showed a set response, or if they did not choose one night for their vacation and their

381 remaining response pattern identified them as straight-liners. The final sample comprised 684

382 participants from Switzerland (German-speaking regions), comprising $52 \%$ females and $48 \%$ 
males. The participants were aged between 18 and $70(M=43.72, S D=14.67)$. Approximately

384 half of the sample had a medium level of education (49\%), 19\% had a lower level of education, 385 and $32 \%$ had a higher level of education. These sociodemographic variables were included in the 386 analysis.

\section{$387 \quad 3.5$ Measurement}

388 To test the validity of the manipulations, a manipulation check was included in the questionnaire, 389 wherein the participants were asked to rate the valence of the customer rating on an eleven-point 390 scale using a vertical slider $(1=$ positive to $6=$ balanced to $11=$ negative $)$. Separately from the 391 advertisements, the participants were shown all three customer ratings (rated poor vs. mediocre 392 vs. good) side by side to judge the valence of each customer rating. In addition, the participants 393 were asked to rate the level of the certified sustainability on an eleven-point scale using a vertical 394 slider $(1$ = strong (in all dimensions very much) to $11=$ weak (only in a few dimensions)). To 395 make it possible for the participants to differentiate the levels of sustainability certification, the 396 questionnaire provided a short introduction to the dimensions of sustainability, including 397 information on the indicators of strong and weak engagement in sustainability. Depending on the 398 experimental group, the participants had to evaluate either the three different sustainability labels 399 or the three different sustainability rating pictograms. Separately from the advertisements, the 400 participants were shown all three sustainability certifications (level one vs. two vs. three) side by 401 side to judge the sustainability certification level (see appendix B).

To measure the interest in obtaining further information about the offer, Matthes's (2006)

403 scale was used with adjustments. Interest was measured on a seven-point Likert scale by three 404 items (e.g., I would like to learn more about the products and services of this hotel. $1=$ strongly 405 disagree to $7=$ strongly agree, see appendix B). This interest in further information was 
406

407

408

409

410

411

412

413

\section{$414 \quad$ 4.1 Manipulation checks}

415 The participants evaluated the diverse customer ratings as significantly different $(F(1.35,915.91)$

$416=138.06, p<.001$, partial $\left.\eta^{2}=.169\right)$. Mauchly's test indicated that the assumption of sphericity

417 had been violated $\left(\chi^{2}(2)=450.40, p<.001\right)$; therefore, the results of Greenhouse-Geisser

418 correction tests are reported $(\varepsilon=.67)$. The more circles that were highlighted, the more positive

419 the customer rating was estimated to be by the participants $\left(M_{\text {four and a half circles }}=2.61, S D=1.50\right.$,

$\left.420 \quad M_{\text {three circles }}=5.10, S D=1.30, M_{\text {one circle }}=8.47, S D=2.36\right)$. The results revealed that the high

421 customer rating condition was evaluated as significantly more positive than the middle condition

$422\left(F(1,680)=100.18, p<.001\right.$, partial $\left.\eta^{2}=.128\right)$, and the low customer rating condition was

423 evaluated as significantly more negative than the middle condition $(F(1,680)=109.45, p<.001$,

$\left.424 \operatorname{partial} \eta^{2}=.139\right)$. These results indicated that the manipulation of the customer rating was

425 successful.

426 To verify if the three different labels were indistinguishable to the participants, an

427 equivalence test (Frick, 1996; Weber \& Popova, 2012) was conducted. The results indicated that

428 the manipulation was successful. The participants in the condition Green Key (environmental) 
$429(M=5.14, S D=1.93)$ did not indicate that this label certifies fewer sustainability dimensions

430 than Viabono (environmental and economic) $\left(M=5.40, S D=1.68, t(345)=-2.42, \Delta=.20, p_{\text {eq }}\right.$

$431=.033$ (two-tailed)) or Travelife (environmental, social and economic) $(M=4.96, S D=1.79$,

$432 t(345)=1.53, \Delta=.20, p_{\text {eq }}=.003$ (two-tailed)). Additionally, there was no observed difference

433 between the results for Viabono (environmental and economic) and Travelife (environmental,

434 social and economic) $\left(t(345)=4.67, \Delta=.30, p_{\text {eq }}=.035\right.$ (two-tailed)). These results indicated that

435 although the participants viewed different labels, they could not estimate the level of

436 sustainability (one vs. two vs. three) certified by the labels.

437 The participants evaluated the diverse sustainability rating pictograms as significantly

438 different $\left(F(1.25,418.07)=72.79, p<.001\right.$, partial $\left.\eta^{2}=.179\right)$. The results of the Greenhouse-

439 Geisser correction tests are reported $(\varepsilon=.63)$ because the Mauchly's test indicated that the 440 assumption of sphericity had been violated $\left(\chi^{2}(2)=303.30, p<.001\right)$. The more lotus flowers

441 that were highlighted, the higher the perceived sustainability level $\left(M_{\text {five flowers }}=2.11, S D=1.66\right.$,

$\left.442 M_{\text {three flowers }}=5.31, S D=1.17, M_{\text {one and a half flowers }}=8.37, S D=1.95\right)$. The results indicated that the

443 sustainability rating condition three was significantly evaluated as showing a higher level of

444 sustainability than the condition two $\left(F(1,334)=74.15, p<.001\right.$, partial $\left.\eta^{2}=.182\right)$, and the

445 sustainability rating condition one was significantly evaluated as showing a lower level of

446 sustainability than the condition two $\left(F(1,334)=46.64, p<.001\right.$, partial $\left.\eta^{2}=.123\right)$. These results

447 indicated that the manipulation of the rating pictogram regarding the level of sustainability (one

448 vs. two vs. three) was successful.

\section{$449 \quad 4.2$ Effect of customer rating}

450 The influence of the customer ratings (H1) and sustainability certification (H2 and $\mathrm{H} 3)$ as

451 well as the additive effect of both informational cues (H5) on consumers' interest were tested by 
452 a repeated measures analysis of variance (ANOVA). The customer ratings (poor vs. mediocre vs.

453 good) and sustainability levels (one vs. two vs. three) were included as within factors, and the

454 certification system (label vs. rating pictogram) was included as a between factor. The interest in

455 obtaining further information about the offer served as the dependent variable, and

456 sociodemographic variables (gender, age and education) were used as controls.

457 A significant main effect of customer rating $(\mathrm{H} 1)$ was found $(F(1.40,953.69)=28.70, p$

$458<.001$, partial $\left.\eta^{2}=.041\right)$. The assumption of sphericity had been violated $\left(\chi^{2}(2)=373.94, p\right.$

$459<.001)$; therefore, the Greenhouse-Geisser correction tests are reported $(\varepsilon=.70)$. The better a

460 hotel was evaluated by a customer rating, the higher the need for information $\left(M_{\text {one circle }}=3.03\right.$,

$\left.461 S D=1.24, M_{\text {three circles }}=4.48, S D=1.05, M_{\text {four and a half circles }}=5.47, S D=1.12\right)$. The results showed

462 that high customer ratings led to a stronger interest in further information than the middle

463 customer rating condition $\left(F(1,679)=30.89, p<.001\right.$, partial $\left.\eta^{2}=.044\right)$. Similarly, the middle

464 customer rating condition led to a stronger interest in further information than the low customer

465 rating condition $\left(F(1,679)=10.42, p=.001\right.$, partial $\left.\eta^{2}=.015\right)$. Therefore, the results confirmed

466 the first hypothesis, which proposed that higher customer ratings lead to a higher interest in the

467 offer.

$468 \quad 4.3$ Effect of sustainability certifications

469 The conducted repeated measures ANOVA showed a significant interaction effect of the

470 level of sustainability and the certification system $(\mathrm{H} 2$ and $\mathrm{H} 3)$ on the interest in further

471 information $\left(F(1.77,1202.54)=91.39, p<.001\right.$, partial $\left.\eta^{2}=.119\right)$. This interaction effect

472 indicates that the influence of the level of sustainability on the interest in information depends on

473 the certification system. To break down this interaction, each level of sustainability certification

474 was compared across the two experimental groups (label vs. rating pictogram). This comparison 
475 revealed a significant difference in the scores of participants who viewed labels and those who 476 viewed rating pictograms for level three and two of sustainability $(F(1,679)=51.16, p<.001$, 477 partial $\eta^{2}=.070$ ). Similarly, the difference in the level of interest of the two experimental groups 478 varied between the conditions two and one $\left(F(1,679)=60.09, p<.001\right.$, partial $\left.\eta^{2}=.081\right)$. The 479 interaction graph shows (see Fig. 1) that different labels did not influence the interest in 480 obtaining further information $\left(M_{\text {Key }}=4.25, S D=0.99, M_{\text {Viabono }}=4.29, S D=0.98, M_{\text {Travelife }}=\right.$ $4814.27, S D=1.02)$. Furthermore, the graph shows that when the level of sustainability is three and 482 the level is certified by a sustainability rating pictogram, the interest in information about the 483 offer was higher than condition two, and this condition did lead to a higher interest than the 484 sustainability level one $\left(M_{\text {one and a half flowers }}=3.90, S D=0.99, M_{\text {three flowers }}=4.38, S D=0.98, M_{\text {five }}\right.$ 485 flowers $=4.87, S D=1.02$ ). Therefore, the results confirmed hypothesis two and three: First, the 486 participants did not show different amounts of interest if the sustainability level was certified by 487 labels (H2). Second, the participants showed an increased interest in obtaining further 488 information if the sustainability level was higher and if it was certified by rating pictograms 489 (H3). 
Fig. 1 Interaction effect of sustainability level and certification system

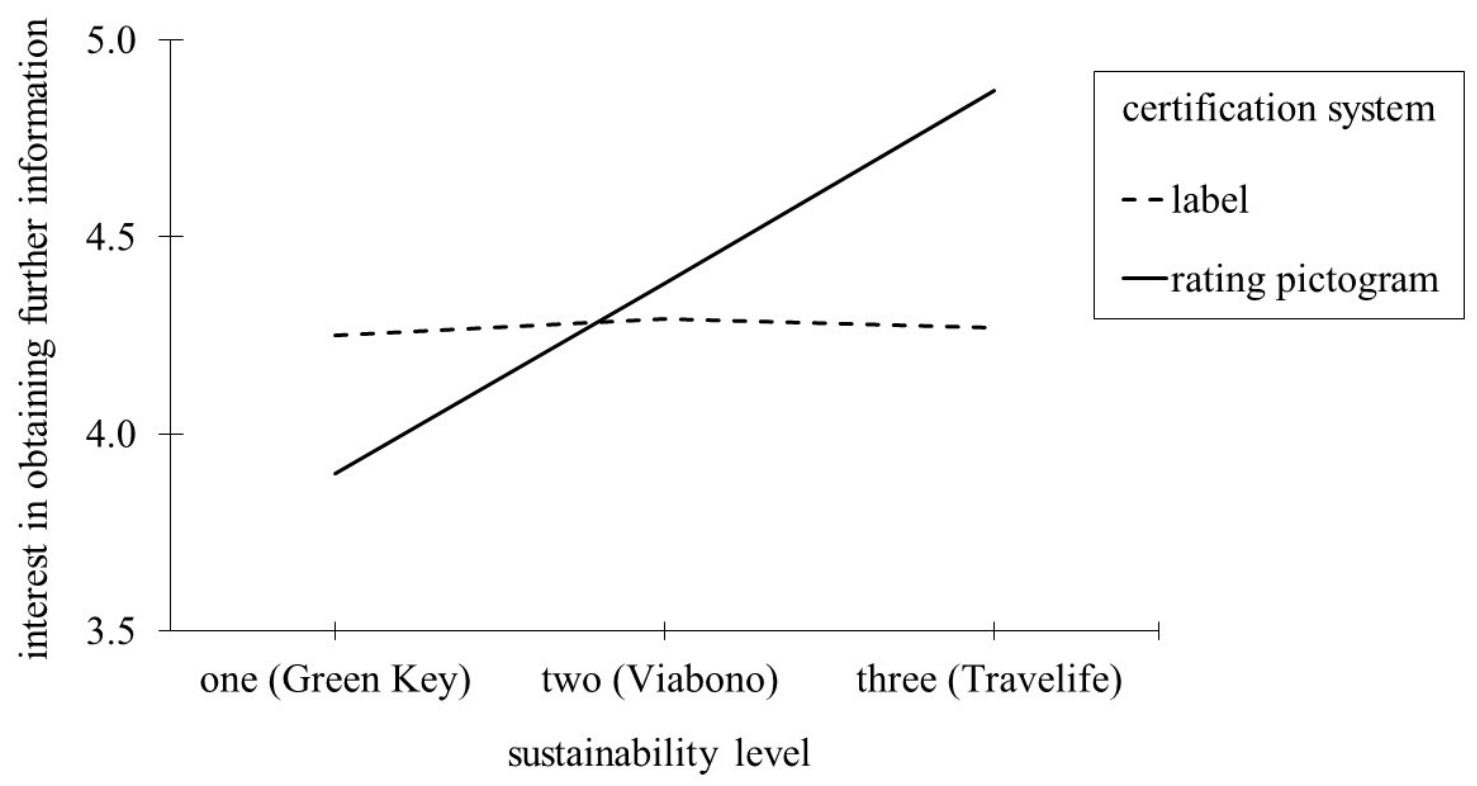

491

To test if sustainability rating pictograms resulted in higher consumer trust than

493 sustainability labels (H4), a one-way ANOVA was conducted. The between factor (label vs.

494 rating pictogram) served as the independent variable, trust in the sustainability certification was

495 the dependent variable, and sociodemographic variables (gender, age and education) were

496 control items. The results confirmed the fourth hypothesis, that the participants who viewed

497 rating pictograms had significantly stronger trust in the sustainability certification $(M=4.50, S D$

$498=1.28)$ than the participants who viewed the labels $(M=4.16, S D=1.29), F(1,679)=10.90, p$

$499=.001$, partial $\eta^{2}=.016$. Thus, the fourth hypothesis was confirmed.

\section{$500 \quad$ 4.4 The additive effect}

501 The three-way interactive effect of the repeated measure ANOVA was not significant $(F(3.91$,

$5022654.61)=1.31, p=.263$, partial $\left.\eta^{2}=.002\right)$. However, in this study, an additive effect for

503 participants who viewed rating pictograms as the sustainability certification and not for

504 participants who viewed labels as the sustainability certification was expected (H5). Therefore, a 
505 data split was conducted (certification system: label vs. rating pictogram). Then, a repeated

506 ANOVA with the customer ratings (poor vs. mediocre vs. good) and sustainability level (one vs.

507 two vs. three) as within factors implemented. The interest in obtaining further information about

508 the offer served as the dependent variable, and sociodemographic variables (gender, age and

509 education) were used as controls. The results of this ANOVA confirmed the fifth hypothesis: In

510 addition to the main effect of the customer rating $\left(F(1.36,456.07)=26.62, p<.001\right.$, partial $\eta^{2}$

$511=.074)$, the main effect of the sustainability level was significant if the levels were illustrated by

512 rating pictograms $\left(F(1.63,544.09)=6.54, p=.003\right.$, partial $\left.\eta^{2}=.019\right)$. The interaction graph (see

513 Fig. 2) shows that the level of sustainability certified by a rating pictogram influences the interest

514 in information in addition to the customer ratings. Hence, the better a hotel is evaluated by

515 consumers (customer rating), the higher the interest in obtaining further information, and this

516 interest can be increased by a higher level of sustainability if it is illustrated by a rating

517 pictogram. However, if the participants viewed different labels that certified the sustainability of

518 the product, interest in further information was influenced exclusively by the customer rating

$519\left(F(1.45,494.71)=6.82, p=.004\right.$, partial $\left.\eta^{2}=.020\right)$, not by the level of sustainability.

520 Consequently, the fifth hypothesis was also confirmed. 
521 Fig. 2 Interaction effect of customer rating and sustainability level shown as rating pictogram

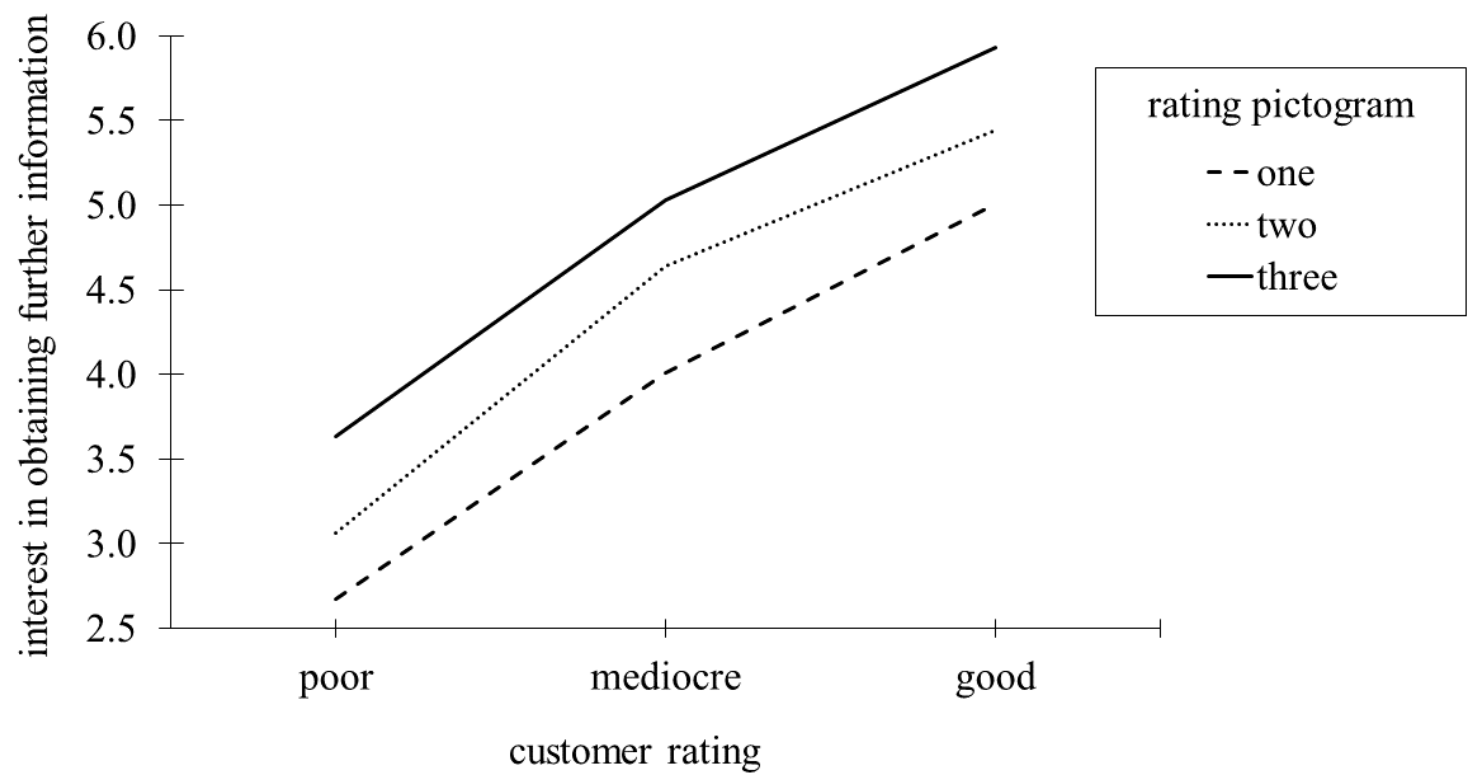

5 Discussion

524 The current study clarifies that rating pictograms are a preferred method as opposed to common

525 sustainable hotel labels to foster customer interest. Since the idea of sustainable tourism began in 526 the 1980s, the use of labels has increased to certify this type of tourism and hotels that implement 527 sustainability initiatives, particularly taking off in the mid-1990s (Fairweather et al., 2005; Graci 528 \& Dodds, 2015). However, the effectiveness of sustainability labels has been contested (Dendler, 529 2014; Fairweather et al., 2005; Font, 2002; Horne, 2009; Rex \& Baumann, 2007). Consumers 530 have difficulties verifying the truthfulness and meaning of these labels. Consumers have

531 suspicions that hotels do not operate in a sustainable way but rather use the labels to increase the 532 value of their companies. Therefore, they have a certain amount of mistrust in labels. They 533 perceive labels as commercial, while they consider rating scales to be noncommercial (De 534 Langhe, Fernbach, \& Lichtenstein, 2016; Ha, 2002). 
In addition to this trust component, rating pictograms provide information that is not

536 included in labels. Therefore, a rating pictogram is understandable for the customer, and

537 customers include the information provided by this cue in their consideration. A label can certify

538 a hotel's sustainability efforts; however, it does not show a compliance rate or scope. The

539 different certification programs include a diversity of criteria, and a hotel must fulfill a certain

540 amount of such criteria to obtain a label as a certification award. Hence, the label symbol does

541 not visualize how many from all potential reachable criteria are covered by the hotel. In addition

542 to identifying the compliance rate, theoretically it would be simpler to identify the scope of the

543 certification program represented by the label. However, consumers cannot differentiate among

544 the numerous different labels or determine which dimensions of sustainability are certified. A

545 hotel can show that it focuses on specific sustainability aspects only by purchasing more than

546 one label; however, consumers still do not understand the meaning behind each and every label.

547 They do not understand if the label represents a certification program with a scope that includes

548 only environmental sustainability or a broader scope that considers all three dimensions of

549 sustainability. Consequently, they do not consider different labels when deciding about the

550 attractiveness of several hotel offers.

551 In contrast, sustainability rating pictograms readily show the level of sustainability

552 because consumers have a reference point. It is easier to discern the highest and lowest levels of 553 sustainability or the amount of sustainability dimensions. Hence, a standardized catalogue of

554 sustainability criteria could be used, for example, the criteria of the Global Sustainable Tourism

555 Council (GSTC, 2017), to measure the compliance rate of each hotel. Then, these compliance

556 rates can be visualized by a uniform rating pictogram that is similar to the one used in this

557 experiment. In this way, every hotel is certified by the same symbol, and therefore, hotels' 
558 sustainability efforts are comparable to one another. Finally, if sustainability is an important

559 aspect for consumers, they use this informational cue and base their decisions on it.

560 Furthermore, the results of this experiment confirm the significant impact of consumer-

561 generated reviews, particularly the effect of summarized customer ratings during the early phase

562 of the decision-making process. Consistent with Gavilan and colleagues' (2018) findings,

563 positive customer ratings increase the demand for additional information about the offer. The

564 driving force of consumers' interest in receiving more details and the perceived attractiveness of

565 a hotel is based on a summarized numerical customer rating. Any other specific quality attribute

566 increases the demand if the corresponding informational cue is presented in a comprehensible

567 way. Consumers base their decisions regarding whether a hotel offer is attractive first on the

568 valence of the overall customer rating and second on the extent of additional quality attributes,

569 such as sustainability. However, the consumer must be able to comprehend the informational cue

570 that represents the level of sustainability.

571 In sum, to reduce informational overload and to be able to quickly select a hotel from

572 several offers on diverse websites, people respond to quality signs. Customer ratings are a well-

573 established and effective informational cue, which is used in classified ads. The better a hotel is

574 evaluated, the higher its perceived attractiveness will be. Furthermore, sustainability attributes

575 are increasingly important to consumers and affect their booking decisions. Hence, it is

576 indispensable to use sustainability rating pictograms as a persuasive cue that is provided along

577 with the initial information presented to a potential consumer, which could be presented as

578 abbreviated information that briefly describes the offer. 


\section{Limitations and practical implementations}

This study offers new insights into the effectiveness of sustainability certifications.

581 Therefore, three labels were categorized according to the scope of the associated certification

582 program. Considering the complexity of certification programs, such simplified categorization is

583 insufficient. In this experiment, the levels of sustainability certified by labels and by rating

584 pictograms were not directly comparable. Labels vary in terms of the number of the

585 sustainability dimensions they certify, whereas rating pictograms more generally show a

586 compliance rate for sustainability. However, this experiment shows that the rating pictogram is a

587 more useful symbol to the customer. Practically stated, pictograms are versatile: Such

588 informational cues can be used to show the compliance rate based on a comprehensive

589 sustainability criteria catalogue, to represent the number of sustainability dimensions that are

590 covered by the hotel, or to visualize the compliance rate for each of the three sustainability

591 dimensions. However, this type of informational cue makes it possible for the customer to

592 differentiate among hotels' sustainability efforts, and therefore, it is used during the selection

593 phase. Further, a sustainability label is a symbol that does not include any information for

594 comparison and therefore is not used as information during the early stage of the decision595 making process.

596 Although the experiment confirmed that consumers trust sustainability rating pictograms

597 more than sustainability labels, whether the participants were more familiar with rating scales or

598 whether they perceived rating scales as more noncommercial was not explicitly measured.

599 However, their familiarity with rating scales was derived from the evidence of general practice,

600 because every booking page and most online shopping websites integrate consumer-generated

601 customer ratings as a standard. The noncommercial character of the sustainability rating 
602 pictogram was incorporated into the stimuli as 'Sustainability certified; independent on-site

603 verification' was written under each sustainability rating pictogram. Consequently, the statements

604 about familiarity and perceived commerciality are correctly deducted, even if these constructs

605 are not measured.

Because this investigation focused on the effects of two informational cues (customer

607 ratings and sustainability certifications), other factors influencing the decision-making process

608 were measured and not manipulated within this research. Several hotel attributes, such as

609 location, size, room quality, price, and cleanliness, affect consumers' booking behavior

610 (Radojevic, Stanisic, \& Stanic, 2015; Ramanathan \& Ramanathan, 2011). This study did not

611 examine the effect of every factor but did investigate the influence of the overall customer rating

612 that includes most aspects because it is a total evaluation of the hotel. Additionally, such

613 summarized customer ratings are usually presented to tourists in an early stage of the decision-

614 making process and are considered to be important influential factors in online booking behavior

615 (Dickinger \& Mazanec, 2008; Gavilan, Avello, \& Martinez-Navarro, 2018). To summarize, the

616 customer rating is an informational cue that includes all the tangible and intangible aspects of the

617 hotel that influence the booking decision, and it is therefore a very persuasive factor in the early

618 stage of the selection process. Furthermore, other factors that massively influence the decision to

619 obtain further information were integrated within the experiment. The experimental setting was

620 therefore very realistic, and key attributes were included to measure the actual effect of such

621 informational cues (customer ratings and sustainability certifications). Hence, practitioners can

622 use the results of this study to create classified ads that are persuasive to the customer. First, they

623 must be aware of the high impact of an overall customer rating. Second, they now know that

624 sustainability is a hotel attribute that affects booking behavior when other, necessary hotel 
625 attributes are fulfilled and when the sustainability level is communicated in an easy-to-interpret 626 way.

\section{Conclusion}

The current experiment is the first empirical study in the field of sustainable tourism

629 marketing that has a remarkably high level of external and internal validity. Since the advent of

630 sustainable tourism, the question of how to best market this type of tourism has persisted. The

631 problem is that the price (Chiang \& Jang, 2007), location (Kozak \& Rimmington, 1999), rooms

632 (Zhang, Ye, \& Law, 2011), and brand (Chiang \& Jang, 2007) of the hotel are always

633 overwhelming predictors in the decision-making process, regardless of whether the hotel is

634 sustainable. However, on booking websites, tourists usually preselect a price range, a travel date,

635 and a destination to obtain a selection of hotels that meet these criteria. The current study

636 included a selection task that replicated this real booking scenario (external validity) with the

637 advantage of controlling for these personal preference predictors (internal validity). After this

638 first selection process, consumers make their next selection. Tourists choose hotel offers for

639 further consideration based on advertisements containing a limited amount of information such

640 as a picture of the hotel, the hotel name, the location, information and map pictograms, customer

641 rating, and sustainability certification. By rebuilding these classified hotel ads, it was possible to

642 ensure high external validity. Because the pictures and names were pretested and assigned

643 randomly to the manipulated conditions, it was also possible to ensure high internal validity.

644 Therefore, the influence of customer ratings and sustainability certifications can be confidently

645 traced back to the manipulation. If a hotel is certified with regard to its sustainability by a rating

646 pictogram, the level of sustainability will influence consumers' choice in addition to the

647 customer rating. Further studies and practical implementations should therefore consider 
648 favoring rating pictograms for inclusion in advertisements for sustainable products and services.

649 This sustainability certification should be based on a defined number of criteria that vary among

650 countries and types of offers. A global body must be created to monitor compliance and

651 communicate these criteria. 


\section{References}

653 Barth, M., Weber, F., \& Güntensperger, M. (2011). Durchblick im Label-Dschungel [Navigating through the jungle of labels] (Ergebnisse des Nachhaltigkeits-Seminars anlässlich der Winter-Delegiertenversammlung 2010) (pp. 1-31). Bern: hotelleriesuisse. Retrieved from

BFS (2018). Bruttoinlandprodukt pro Einwohner. [Gross domestic product per inhabitant] Retrieved from /alle-indikatoren/wirtschaft/reales-bip-pro-kopf.assetdetail.6028921.html

Bickart, B. A., \& Ruth, J. A. (2012). Green Eco-Seals and Advertising Persuasion. Journal of https://www.bfs.admin.ch/bfs/de/home/statistiken/querschnittsthemen/wohlfahrtsmessung Advertising, 41(4), 51-67. doi: 10.2753/JOA0091-3367410404

Buckley, R. (2002). Tourism ecolabels. Annals of Tourism Research, 29(1), 183-208. doi: 10.1016/S0160-7383(01)00035-4

Buhalis, D., \& Law, R. (2008). Progress in information technology and tourism management: 20 years on and 10 years after the Internet-The state of eTourism research. Tourism Management, 29(4), 609-623. doi: 10.1016/j.tourman.2008.01.005

Casaló, L. V., Flavián, C., Guinalíu, M., \& Ekinci, Y. (2015). Do online hotel rating schemes influence booking behaviors? International Journal of Hospitality Management, 49, 28guests. Journal of Retailing and Consumer Services, 22, 261-265. doi: 10.1016/j.jretconser.2014.08.007 
674 Chen, Y., \& Xie, J. (2008). Online Consumer Review: Word-of-Mouth as a New Element of 675 Marketing Communication Mix. Management Science, 54(3), 477-491. doi: 10.1287/mnsc. 1070.0810

677 Chiang, C.-F., \& Jang, S. S. (2007). The Effects of Perceived Price and Brand Image on Value and Purchase Intention: Leisure Travelers' Attitudes Toward Online Hotel Booking. Journal of Hospitality \& Leisure Marketing, 15(3), 49-69. doi: 10.1300/J150v15n03_04

Clemons, E. K., Gao, G., \& Hitt, L. M. (2006). When Online Reviews Meet Hyperdifferentiation: A Study of the Craft Beer Industry. Journal of Management Information Systems, 23(2), 149-171.

De Langhe, B., Fernbach, P. M., \& Lichtenstein, D. R. (2016). Navigating by the Stars: Investigating the Actual and Perceived Validity of Online User Ratings. Journal of Consumer Research, 42(6), 817-833. doi: 10.1093/jcr/ucv047

Decrop, A., \& Boembeke, V. (2017). The importance of quality labels in consumers' preferences. In A. Correia, M. Kozak, J. Gnoth, \& A. Fyall (Eds.), Co-creation and well-being in

Dendler, L. (2014). Sustainability Meta Labelling: an effective measure to facilitate more sustainable consumption and production? Journal of Cleaner Production, 63, 74-83. doi:

693 Dickinger, A., \& Mazanec, J. (2008). Consumers' Preferred Criteria for Hotel Online Booking. In Information and Communication Technologies in Tourism 2008 (pp. 244-254). 
696

697

698

699

700

701

702

703

704

705

706

707

708

709

710

711

712

713

714

715

716

717

Emberger-Klein, A., \& Menrad, K. (2018). The effect of information provision on supermarket consumers' use of and preferences for carbon labels in Germany. Journal of Cleaner Production, 172, 253-263. doi: 10.1016/j.jclepro.2017.10.105

Fairweather, J. R., Maslin, C., \& Simmons, D. G. (2005). Environmental Values and Response to Ecolabels Among International Visitors to New Zealand. Journal of Sustainable Tourism, 13(1), 82-98. doi: 10.1080/17501220508668474

Filieri, R., \& McLeay, F. (2014). E-WOM and accommodation: An analysis of the factors that influence travelers' adoption of information from online reviews. Journal of Travel Research, 53(1), 44-57.

Font, X. (2002). Environmental certification in tourism and hospitality: progress, process and prospects. Tourism Management, 23(3), 197-205. doi: 10.1016/S0261-5177(01)00084-X

Frick, R. W. (1996). The appropriate use of null hypothesis testing. Psychological Methods, 1(4), 379-390. doi: 10.1037/1082-989X.1.4.379

Frydendal, J., Hansen, L. E., \& Bonou, A. (2018). Environmental Labels and Declarations. In Life Cycle Assessment (pp. 577-604). Cham: Springer.

Gavilan, D., Avello, M., \& Martinez-Navarro, G. (2018). The influence of online ratings and reviews on hotel booking consideration. Tourism Management, 66, 53-61. doi: 10.1016/j.tourman.2017.10.018

Gefen, D. (2000). E-commerce: the role of familiarity and trust. Omega, 28(6), 725-737. doi: 10.1016/S0305-0483(00)00021-9

Gössling, S., \& Buckley, R. (2016). Carbon labels in tourism: persuasive communication? Journal of Cleaner Production, 111, Part B, 358-369. doi: 10.1016/j.jclepro.2014.08.067 
718 Graci, S., \& Dodds, R. (2015). Certification and labeling. In C. M. Hall, S. Gossling, \& D. Scott

719 (Eds.), The Routledge Handbook of Tourism and Sustainability (pp. 200-208). London:

$720 \quad$ Routledge.

721 Grunert, K. G., Hieke, S., \& Wills, J. (2014). Sustainability labels on food products: Consumer 722 motivation, understanding and use. Food Policy, 44, 177-189. doi: 10.1016/j.foodpol.2013.12.001

GSTC (2017). GSTC Criteria Overview. Retrieved from https://www.gstcouncil.org/gstc-criteria/

725 Guillet, B. D., \& Law, R. (2010). Analyzing hotel star ratings on third-party distribution websites. International Journal of Contemporary Hospitality Management, 22(6), 797813. doi: 10.1108/09596111011063098

Ha, H.-Y. (2002). The Effects of Consumer Risk Perception on Pre-purchase Information in Online Auctions: Brand, Word-of-Mouth, and Customized Information. Journal of Computer-Mediated Communication, 8(1). doi: 10.1111/j.1083-6101.2002.tb00160.x

731 Hasher, L., Goldstein, D., \& Toppino, T. (1977). Frequency and the conference of referential validity. Journal of Verbal Learning and Verbal Behavior, 16(1), 107-112. doi:

734 Horne, R. E. (2009). Limits to labels: The role of eco-labels in the assessment of product sustainability and routes to sustainable consumption. International Journal of Consumer Studies, 33(2), 175-182. doi: 10.1111/j.1470-6431.2009.00752.x $10.1016 / \mathrm{S} 0022-5371(77) 80012-1$ 
740 Jiang, P., Jones, D. B., \& Javie, S. (2008). How third-party certification programs relate to $741 \quad$ consumer trust in online transactions: An exploratory study. Psychology \& Marketing, $742 \quad 25(9), 839-858$.

743 Kozak, M., \& Nield, K. (2004). The Role of Quality and Eco-Labelling Systems in Destination 744 Benchmarking. Journal of Sustainable Tourism, 12(2), 138-148. doi: $10.1080 / 09669580408667229$

746 Kozak, M., \& Rimmington, M. (1999). Measuring tourist destination competitiveness: conceptual considerations and empirical findings. International Journal of Hospitality Management, 18(3), 273-283. doi: 10.1016/S0278-4319(99)00034-1

749 Labelinfo.ch. (2018, January 3). Für den Durchblick im Label-Dschungel [For Navigating through the jungle of labels]. Retrieved from http://www.labelinfo.ch/de/labels?\&t=0\&compare=136,21,16,165,72,155,127,147,118,12 $4,190,35,60,213,59,174,26,123$

753 Ladhari, R., \& Michaud, M. (2015). eWOM effects on hotel booking intentions, attitudes, trust, and website perceptions. International Journal of Hospitality Management, 46(Supplement C), 36-45. doi: 10.1016/j.ijhm.2015.01.010

756 Lee, J., Park, D.-H., \& Han, I. (2008). The effect of negative online consumer reviews on product attitude: An information processing view. Electronic Commerce Research and Applications, 7(3), 341-352. doi: 10.1016/j.elerap.2007.05.004

Lee, M. K. O., \& Turban, E. (2001). A Trust Model for Consumer Internet Shopping. International Journal of Electronic Commerce, 6(1), 75. 
761 Lien, C.-H., Wen, M.-J., Huang, L.-C., \& Wu, K.-L. (2015). Online hotel booking: The effects of brand image, price, trust and value on purchase intentions. Asia Pacific Management Review, 20(4), 210-218. doi: 10.1016/j.apmrv.2015.03.005

Litvin, S. W., Goldsmith, R. E., \& Pan, B. (2008). Electronic word-of-mouth in hospitality and tourism management. Tourism Management, 29(3), 458-468. doi: 10.1016/j.tourman.2007.05.011

Lübbert, C. (2001). Tourism ecolabels market research in Germany. In X. Font, \& R. Buckley (Eds.), Tourism ecolabelling: certification and promotion of sustainable management. Wallingford: CAB International.

Matthes, J. (2006). The Need for Orientation Towards News Media: Revising and Validating a Classic Concept. International Journal of Public Opinion Research, 18(4), 422-444. doi: 10.1093/ijpor/edh118

Mauri, A. G., \& Minazzi, R. (2013). Web reviews influence on expectations and purchasing intentions of hotel potential customers. International Journal of Hospitality Management, 34, 99-107. doi: 10.1016/j.ijhm.2013.02.012

Naderer, B., Schmuck, D., \& Matthes, J. (2017). Greenwashing: Disinformation through Green Communication in the Digital Age: Information or Disinformation? Berlin/Boston: Walter de Gruyter. 
782 Niederberger, C. (2017, June). The Impact of Hotel Sustainability Certifications on Customer

783 Online Rating in Vienna, Austria: A Comparison of the Years 2013 \& 2016. Hochschule

784 Luzern, Luzern.

785 Öğ̈̈t, H., \& Onur Taş, B. K. (2012). The influence of internet customer reviews on the online

786 sales and prices in hotel industry. Service Industries Journal, 32(2), 197-214. doi:

$787 \quad 10.1080 / 02642069.2010 .529436$

788 Park, S.-Y., \& Millar, M. (2016). The US traveler's familiarity with and perceived credibility of lodging ecolabels. Journal of Vacation Marketing, 22(1), 3-12. doi: $10.1177 / 1356766715585904$

791 Plüss, C., Zotz, A., Monshausen, A., \& Kühhas, C. (2016). Nachhaltigkeit im Tourismus. Wegweiser durch den Labeldschungel [Sustainability in tourism. Signpost through the jungle of labels] (pp. 1-23). Wien/Basel/Saarbrücken/Berlin: Naturfreunde Internationale/arbeitskreis tourismus \& entwicklung/ECOTRANS e.V./Brot für die Welt -

Pröbstl, U., \& Müller, F. (2012). Hotel certification and its relevance for sustainable development: examples from the European Alps. Sustainable Tourism V, 161, 3.

800 Radojevic, T., Stanisic, N., \& Stanic, N. (2015). Ensuring positive feedback: Factors that influence customer satisfaction in the contemporary hospitality industry. Tourism Management, 51, 13-21. doi: 10.1016/j.tourman.2015.04.002 
803 Ramanathan, U., \& Ramanathan, R. (2011). Guests’ perceptions on factors influencing customer

$804 \quad$ loyalty: An analysis for UK hotels. International Journal of Contemporary Hospitality Management, 23(1), 7-25. doi: 10.1108/09596111111101643

806 Rex, E., \& Baumann, H. (2007). Beyond ecolabels: what green marketing can learn from conventional marketing. Journal of Cleaner Production, 15(6), 567-576. doi: 10.1016/j.jclepro.2006.05.013

Rhee, H. T., \& Yang, S.-B. (2015). Does hotel attribute importance differ by hotel? Focusing on hotel star-classifications and customers' overall ratings. Computers in Human Behavior, 50, 576-587. doi: 10.1016/j.chb.2015.02.069

Robecosam (2018) Measuring country intangibles. Country Sustainability Ranking. Retrieved from http://www.robecosam.com/en/sustainability-insights/about-sustainability/countrysustainability-ranking/index.jsp

818 Serra Cantallops, A., \& Salvi, F. (2014). New consumer behavior: A review of research on eWOM and hotels. International Journal of Hospitality Management, 36, 41-51. doi:

821 Sparks, B. A., \& Browning, V. (2011). The impact of online reviews on hotel booking intentions and perception of trust. Tourism Management, 32(6), 1310-1323. doi: 
824 Sparks, B. A., Kam Fung So, K., \& Bradley, G. L. (2016). Responding to negative online

825

826

827

828

reviews: The effects of hotel responses on customer inferences of trust and concern. Tourism Management, 53, 74-85. doi: 10.1016/j.tourman.2015.09.011

Sparks, B. A., Perkins, H. E., \& Buckley, R. (2013). Online travel reviews as persuasive communication: The effects of content type, source, and certification logos on consumer behavior. Tourism Management, 39, 1-9. doi: 10.1016/j.tourman.2013.03.007

Sun, S., Law, R., Luk, C., \& Fong, L. H. N. (2017). Channels for Searching Hotel and Travel Information. In Information and Communication Technologies in Tourism 2017 (pp. 445458). Cham: Springer.

Tan, H., Lv, X., Liu, X., \& Gursoy, D. (2018). Evaluation nudge: Effect of evaluation mode of online customer reviews on consumers' preferences. Tourism Management, 65, 29-40. doi: 10.1016/j.tourman.2017.09.011

Tepelus, C. M., \& Córdoba, R. C. (2005). Recognition schemes in tourism-from "eco" to “sustainability”? Journal of Cleaner Production, 13(2), 135-140. doi: 10.1016/j.jclepro.2003.12.015

UNEP, \& UNWTO. (2005, September 10). Making tourism more sustainable - A guide for policy makers. Definition. Retrieved from http://sdt.unwto.org/en/content/about-us-5

Unkelbach, C. (2007). Reversing the truth effect: Learning the interpretation of processing fluency in judgments of truth. Journal of Experimental Psychology: Learning, Memory, and Cognition, 33(1), 219-230. doi: 10.1037/0278-7393.33.1.219

Vermeulen, I. E., \& Seegers, D. (2009). Tried and tested: The impact of online hotel reviews on consumer consideration. Tourism Management, 30(1), 123-127. doi:

10.1016/j.tourman.2008.04.008 
847 Weber, R., \& Popova, L. (2012). Testing Equivalence in Communication Research: Theory and Application. Communication Methods \& Measures, 6(3), 190-213. doi: $10.1080 / 19312458.2012 .703834$

WEF (2017). The Travel \& Tourism Competitiveness Report 2017. Paving the way for a more sustainable and inclusive future. Retrieved from http://www3.weforum.org/docs/WEF_TTCR_2017_web_0401.pdf

Willemsen, L. M., Neijens, P. C., Bronner, F., \& de Ridder, J. A. (2011). "Highly Recommended!” The Content Characteristics and Perceived Usefulness of Online Consumer Reviews. Journal of Computer-Mediated Communication, 17(1), 19-38. doi:

Yang, Y., Mueller, N. J., \& Croes, R. R. (2016). Market accessibility and hotel prices in the Caribbean: The moderating effect of quality-signaling factors. Tourism Management, 56, 40-51. doi: 10.1016/j.tourman.2016.03.021

Ye, Q., Law, R., \& Gu, B. (2009). The impact of online user reviews on hotel room sales.

863 Ye, Q., Law, R., Gu, B., \& Chen, W. (2011). The influence of user-generated content on traveler International Journal of Hospitality Management, 28(1), 180-182. doi: behavior: An empirical investigation on the effects of e-word-of-mouth to hotel online

867 Zhang, Z., Ye, Q., \& Law, R. (2011). Determinants of hotel room price: An exploration of bookings. Computers in Human Behavior, 27(2), 634-639. doi: travelers' hierarchy of accommodation needs. International Journal of Contemporary Hospitality Management, 23(7), 972-981. doi: 10.1108/09596111111167551 
870 Zhao, X. (Roy), Wang, L., Guo, X., \& Law, R. (2015). The influence of online reviews to online

871 hotel booking intentions. International Journal of Contemporary Hospitality

872 Management, 27(6), 1343-1364. doi: 10.1108/IJCHM-12-2013-0542 


\section{Appendix A}
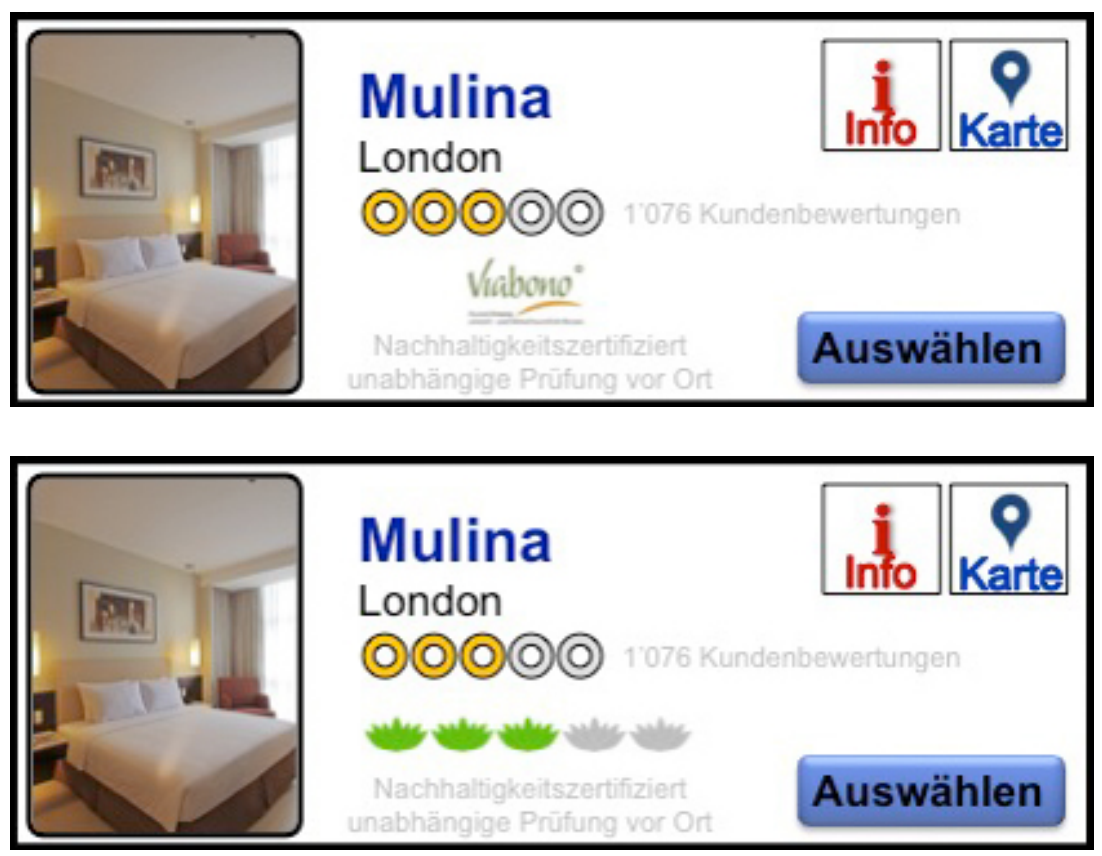

Notes. Two examples of the stimulus material with the manipulated condition customer rating 'mediocre' and sustainability level 'middle'. Above the experimental group with the certification type 'label' and below the experimental group with the certification type 'rating pictogram'. 


\section{Appendix B}

\section{Table 1}

Relevant items measured by the questionnaire

\begin{tabular}{ll}
\hline Variables & \multicolumn{1}{c}{ Item } \\
\hline Sex & $\begin{array}{l}\text { Are you...? } \\
\text { - female // male }\end{array}$ \\
Age & How old are you? \\
Education & Please tick off your highest educational level achieved. \\
& Compulsory education or 1-year pre-apprenticeship, 10th school year; Preparatory vocational education or \\
& diploma school (up to 2 years); Apprenticeship or full-time vocational school // Secondary school for adults; \\
& Diploma middle school (3 years) or teaching; basic vocational training; Teacher seminar (e.g., kindergarten, \\
& subject teachers); Higher technical/vocational training (e.g., Swiss Federal Certificate, Swiss Federal \\
& Diploma) // Higher technical school (for example HTL, HWV); University of Applied Sciences; University \\
& or university degree
\end{tabular}

Manipulation check How do you rate this overall customer rating? Are the corresponding reviews of the hotel guests either negative (customer rating) or positive?

- $\quad$ negative/balanced/positive

Manipulation check What do you think indicates this sustainability certification? Is the hotel more or less committed to sustainability? (sustainability This means that the hotel engages itself more extensively in all three areas (environment, society and economy) level) of sustainability or rather less/only in one dimension.

- $\quad$ weak (only in one dimension)/strong (in all three dimensions)

Interest in obtaining Would you like to know more about the offer?

further information - I would like to learn more about the products and services of this hotel.

- I would like to get details of the offer.

- $\quad$ More detailed information about this hotel would interest me.

How much do you trust in the sustainability certification of the hotel ad?

Trust in the sustainability certification

- I trust this sustainability certification.

$43.72(14.67)$

- I rely on the sustainability of the hotel being checked.

- I believe this sustainability certification is a credible award and a promising sign.

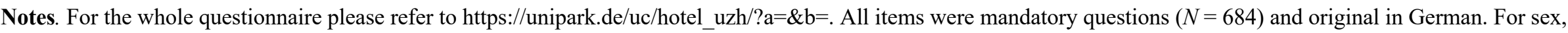

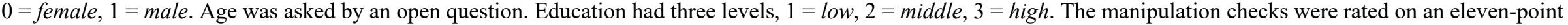

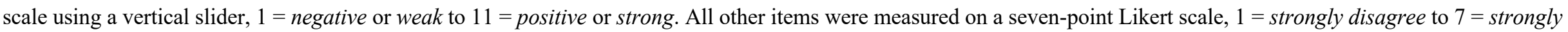
agree. To compare the effects of the different sustainability certifications, both experimental groups (label vs. rating pictogram) received the same questions. 